\title{
Comparison of $50 \mathrm{~g}$ and $100 \mathrm{~g}$ L-tryptophan Depletion and Loading Formulations for Altering 5-HT Synthesis: Pharmacokinetics, Side Effects, and Mood States
}

\author{
Donald M. Dougherty, PhD, \\ Neurobehavioral Research Laboratory and Clinic, Department of Psychiatry, School of Medicine, \\ The University of Texas Health Science Center at San Antonio
}

\section{Dawn M. Marsh-Richard, PhD,}

Neurobehavioral Research Laboratory and Clinic, Department of Psychiatry, School of Medicine, The University of Texas Health Science Center at San Antonio

\author{
Charles W. Mathias, PhD, \\ Neurobehavioral Research Laboratory and Clinic, Department of Psychiatry, School of Medicine, \\ The University of Texas Health Science Center at San Antonio
}

\begin{abstract}
Ashley J. Hood, BS,
Graduate School of Biomedical Sciences, The University of Texas Health Science Center at Houston
\end{abstract}

\section{Merideth A. Addicott, BS, \\ Neuroscience Program, Wake Forest University Health Sciences}

\section{F. Gerard Moeller, MD, \\ Graduate School of Biomedical Sciences, The University of Texas Health Science Center at Houston}

Christopher J. Morgan, MIBiol, and

Department of Medical Biochemistry, University Hospital of Wales, Cardiff

\author{
Abdulla A.-B. Badawy, FRCPath \\ The Cardiff School of Health Sciences, University of Wales Institute Cardiff
}

\section{Abstract}

\begin{abstract}
Rationale-Differences in 5-HT function have been the subject of extensive research in psychiatric studies. Many studies have manipulated $L$-tryptophan (Trp) levels to temporarily decrease (depletion) or increase (loading) 5-HT synthesis. While most researchers have used a $100 \mathrm{~g}$ formulation, there has been ongoing interest in using smaller-sized formulations.
\end{abstract}

Objectives-This study examined the time-course of multiple plasma indicators of brain 5-HT synthesis following $50 \mathrm{~g}$ depletion and loading as a comparison to the typical $100 \mathrm{~g}$ formulation.

\footnotetext{
Please address correspondence to: Donald M. Dougherty, Ph.D., Neurobehavioral Research Laboratory and Clinic, Professor, Department of Psychiatry, Mail Code 7793, School of Medicine, The University of Texas Health Science Center at San Antonio, 7703 Floyd Curl Drive, San Antonio, Texas 78229-3900, USA, Phone: 210-562-6000, Fax: 210-562-6605, doughertyd@uthscsa.edu.

Disclosure/Conflict of Interest

There are no conflicts of interest to report for any of the authors of this manuscript. This study was conducted in compliance with the Declaration of Helsinki and the current laws of the United States of America.
} 
Methods-Plasma was collected from 112 healthy adults at 7 hourly intervals following consumption of either a $50 \mathrm{~g}$ or $100 \mathrm{~g}$ depletion or loading. Self-ratings of mood and somatic symptoms were completed before and after Trp manipulations.

Results-The primary findings were that: (1) the $50 \mathrm{~g}$ and $100 \mathrm{~g}$ formulations produced the expected changes in plasma indicators following both depletion ( $-89 \%$ and $-96 \%$, respectively) and loading $(+570 \%$ and $+372 \%$, respectively); (2) the $100 \mathrm{~g}$ depletion showed more robust effects at the 4,5 , and $6 \mathrm{~h}$ measurements than the 50g depletion; (3) there was significant attrition following both the $100 \mathrm{~g}$ depletion and loading, but not after either $50 \mathrm{~g}$ formulation; and (4) both $50 \mathrm{~g}$ and $100 \mathrm{~g}$ depletions produced increases in negative self-ratings of mood and somatic symptoms, while loading significantly increased negative ratings following the $100 \mathrm{~g}$ only.

Conclusions-There are important considerations when choosing among formulation sizes for use in Trp manipulation studies, and the complete 7-hr time-course data set of the typical plasma Trp measures presented here may help researchers decide which methodology best suits their needs.

\section{Keywords}

$L$-tryptophan; depletion; serotonin; time course; human; competing amino acids; side effects; mood

\section{Introduction}

Serotonin (5-hydroxytryptamine or 5-HT) dysregulation has been related to a wide variety of behavioral, psychiatric, and physical disorders. One of the most popular methodologies for experimentally studying central 5-HT dysregulation has been to increase or decrease the availability of 5-HT's sole precursor, dietary tryptophan (Trp; Fernstrom, 1983), which in turn increases or decreases plasma tryptophan and ultimately 5-HT in the CNS (Biggio et al. 1974; Gessa et al. 1974; Nishizawa et al. 1997; Young et al. 1989). The temporary depletion of 5-HT has typically involved administration of a beverage containing approximately $100 \mathrm{~g}$ of 15 amino acids, lacking Trp, which reduces the bioavailability of Trp. The influx of the 15 amino acids (without Trp) stimulates protein synthesis in the liver, which depletes the body's store of endogenous plasma Trp (Moja et al. 1991; Young, 1993). The bioavailability of Trp for brain 5-HT synthesis is further reduced by the disproportionate increase in plasma concentrations of amino acids (i.e., isoleucine, leucine, phenylalanine, tyrosine, and valine), collectively known as the competing amino acids (CAAs) that compete with Trp for transport across the blood-brain barrier (Fernstrom, 1983). These combined mechanisms maximize the competitive disadvantage for Trp's transport into the brain (e.g., Marsh et al. 2002; Young et al. 1989), ultimately resulting in reduced 5-HT synthesis (Carpenter et al. 1998; Nishizawa et al. 1997; Stancampiano et al. 1997). Alternatively, 5-HT synthesis can also be maintained or increased by adding Trp to the amino-acid formulation. Manipulating Trp availability to increase or decrease brain 5-HT is possible because the rate-limiting enzyme of 5-HT synthesis (i.e., Trp hydroxylase) is approximately 50\% saturated with its Trp substrate (Carlsson and Lindqvist, 1978), which allows for increased or decreased substrate (i.e., Trp) saturation followed by the corresponding changes in 5-HT synthesis.

Trp depletion studies have typically used a 100g dose (e.g., Allen et al. 2006; Gallagher et al. 2003; Murphy et al. 2002; Schmitt et al. 2000; Talbot et al. 2006; Walderhaug et al. 2002), but this size formulation can produce undesirable somatic side effects. These side effects can contribute to participant discomfort and excessive attrition, which could produce a significant loss of data and potentially confound interpretation of results (Marsh et al. 2002). While there are somewhat mixed reports in that some studies have provided no information regarding somatic side effects (e.g., Booij et al. 2005; Dierks et al. 1999; Gallagher et al. 2003; Hughes et al. 2000; Kaye et al. 2000; Knott et al. 1999; Murphy et al. 2002; Smith et al. 1997; Talbot et al. 2006), and others have reported a relative lack of somatic side effects following the $100 \mathrm{~g}$ 
depletion (e.g., Carpenter et al. 1998; Moore et al. 2000; Rubinsztein et al. 2001; Sobczak et al. 2002), there is a sizeable number of studies that have reported undesirable side effects that range from slight nausea and drowsiness to severe nausea and emesis resulting in participant withdrawal from the study (e.g., Allen et al. 2006; Booij et al. 2005; Delgado et al. 1990; Klaassen et al. 1999; Marsh et al. 2002; Moeller et al. 1996; Schmitt et al. 2000; Smith et al. 1986). Based on these reports of somatic side effects, some researchers have specifically attempted to minimize undesirable side effects by reducing the volume of the amino acids used (e.g., Williams et al. 1999; Wolfe et al. 1995), although no comprehensive time course of peripheral indicators of 5-HT synthesis has been conducted for any of the smaller-volume formulations. Nor has there been a comprehensive comparison of the differences in effects of the smaller versus larger size formulations.

Young and colleagues (1989) were one of the first to compare different sizes of amino-acid formulations (i.e., $25 \mathrm{~g}, 50 \mathrm{~g}, 75 \mathrm{~g}$, and $100 \mathrm{~g}$ depletion) taking Trp measurements at baseline and 5 hours following amino-acid administration. Measuring the change from baseline values, they found that the $50 \mathrm{~g}, 75 \mathrm{~g}$, and $100 \mathrm{~g}$ formulations all produced similar depletion at 5 hours after administration, while the $25 \mathrm{~g}$ formulation did not. Furthermore, they found that the effects reach a plateau with a mixture of about $50 \mathrm{~g}$. They concluded that their results "suggest that any advantages in using depletion mixtures larger than $50 \mathrm{~g}$ will be small" (p. 510). In comparing different sizes of amino-acid formulations, the timing of measurement is also of interest. While Young and colleagues used a single post-drink measurement, Moja and colleagues (1988) used four post-drink measurements and demonstrated that their four sizes of the same amino-acid formulation produced maximal depletion at somewhat different times.

Furthermore, some researchers have tested the utility of smaller formulations for obtaining maximal depletion of plasma $L$-tryptophan in sizes ranging from $25 \mathrm{~g}, 36 \mathrm{~g}, 50 \mathrm{~g}, 60 \mathrm{~g}, 75 \mathrm{~g}$, to 85g (e.g., Booij et al. 2005; Dierks et al. 1999; Ellenbogen et al. 1996; Hughes et al. 2000; Murphy et al. 2002; Rubinsztein et al. 2001; Sobczak et al. 2002; Young et al. 1989), and a few have also experimented with different proportions of amino acids (e.g., $36.6 \mathrm{~g}$ of essential amino acids only, Moja et al. 1988, 1989). Although, of the smaller-size formulations, the 50g depletion formulation that is simply a half-size of the typically used $100 \mathrm{~g}$ formulation appears to have been used most often (e.g., Park et al. 1994; Perugini et al. 2003; Porter et al. 2000). While several previous studies have reported time-course measurements of peripheral indicators of 5-HT synthesis (Carpenter et al. 1998; Delgado et al. 1990; Weltzin et al. 1995; Williams et al. 1999) following different $L$-tryptophan formulation types and sizes, to our knowledge there has not been a comprehensive time-course characterization of $50 \mathrm{~g}$ and $100 \mathrm{~g}$ depletion and loading using multiple plasma indicators of 5-HT synthesis (i.e., free and total Trp, the CAAs, and the respective bioavailability ratios). Since Trp manipulations have typically been used to test a particular outcome (e.g., mood or behavior) at a single time point, the contribution of the current study is to compare a complete 7-h plasma time course, along with mood states and somatic side effects, following administration of 50g and $100 \mathrm{~g}$ depletion and loading formulations. While the loading formulation is less commonly used than the balanced control, there are some studies that have elected to use loading as a comparison to depletion (e.g., Bjork et al, 1999, 2000; Cleare \& Bond, 1995; Dougherty et al., 2007; Luciana et al, 2001; Pihl et al. 1995; Riedel et al., 2003), and at least one (Luciana et al. 2001) has found that the loading formulation resulted in negative cognitive outcomes while the depletion formulation did not.

To expand on the work of previous studies, we characterized the time course of $100 \mathrm{~g}$ and $50 \mathrm{~g}$ depletion and loading formulations using multiple measures of plasma Trp (i.e., free and total Trp, the sum of the CAAs, and the respective ratios) across 7 hourly measurements following Trp manipulations and compared their effectiveness for changing plasma Trp measures, mood states, and somatic symptoms. Our expectation was that both the $50 \mathrm{~g}$ and $100 \mathrm{~g}$ formulations 
would produce significant changes in plasma Trp relative to the baseline measurement following both the depletion and loading manipulations. Our primary interest was whether the $100 \mathrm{~g}$ depletion and loading formulations would be more effective for changing plasma measures, mood states, and somatic symptoms, both across time and at peak effects, compared to the $50 \mathrm{~g}$ formulations. As a result, the three aims that guided this study were: (1) to characterize the time course of multiple plasma indicators of brain 5-HT synthesis following Trp depletion and loading for both the $50 \mathrm{~g}$ and $100 \mathrm{~g}$ formulations; (2) to determine whether the $100 \mathrm{~g}$ formulations are more effective than the $50 \mathrm{~g}$ formulations for changing plasma Trp measures; and (3) to determine whether the 50g depletion and loading formulations would be more effective for reducing somatic symptoms that can occur following their respective $100 \mathrm{~g}$ formulations, yet maintain similar effects with regard to mood changes. A secondary aim was to determine whether the two sizes of depletion and loading formulations produced peak effects on plasma measures at different time points.

\section{Materials and Methods}

\section{Participants}

Healthy adults from 18 to 40 years old were recruited through newspaper advertisements in the Houston, TX metropolitan area. Respondents to these advertisements completed a telephone screening, which included information about age, height, weight, and medication/ drug use history. Those who appeared to meet study criteria were invited to the laboratory for an in-depth screening interview. This interview included a psychiatric screening using the Structured Clinical Interview for DSM-IV (SCID-I/NP; First et al. 1997, 2001), and a medical history and physical examination conducted by a nurse practitioner. Participants who were enrolled in the study reported no drug or psychoactive medication use within the last 6 months. Individuals over 40 years old were excluded to avoid potential confounding effects of changes in metabolism with increasing age (e.g., Trp hydroxylase function; Hussain and Mitra, 2000). Other exclusion criteria included: a past or present Axis I psychiatric disorder (including depression and substance abuse/dependence); a past or present physical illness that could affect the central nervous system or Trp metabolism; body mass index (BMI) less than 18 or greater than $30 \mathrm{~kg} / \mathrm{m}^{2}$, or a positive breath-alcohol or urine-drug screen on the day of participation. Qualified participants were pseudo-randomly assigned (within gender) to one of five different amino-acid formulations (described below), and both men and women were administered the same $50 \mathrm{~g}$ and $100 \mathrm{~g}$ formulations. Participants were blind to their assigned experimental condition.

All study procedures were conducted in accordance with the Declaration of Helsinki and approved by the Institutional Review Board at the performance site, the University of Texas Health Science Center at Houston. Following an explanation of study procedures, participants gave written informed consent before screening and acceptance into the study. Each participant was compensated approximately $\$ 75$ for their participation.

\section{Procedure}

Participants completed a screening day followed by a single day of experimental manipulations that included amino-acid beverage consumption, pre- and post-drink self-reports of mood and somatic symptoms, and hourly blood sampling. Participants were instructed to follow a lowmonoamine diet between the screening and testing days. Participants were also instructed to refrain from consuming alcoholic and caffeinated beverages beginning on the night before testing, and to fast after midnight the night before testing. Participants arrived at the laboratory by $0800 \mathrm{~h}$, and fasting was confirmed by self-report. Abstinence from recent alcohol and drug use was confirmed by testing expired-air and urine samples (Alco-Sensor III, Intoximeter, Inc., St. Louis, MO; Syva Rapid Test d.a.u., Syva Co., Dade Behring, Inc., Cupertino, CA). 
Participants were then escorted from the laboratory to the University Clinical Research Center where amino-acid drink administration, self-reported mood and somatic symptoms ratings, and blood sampling procedures were conducted.

The testing day lasted from 0800 to $1630 \mathrm{~h}$. Participants completed a baseline assessment of subjective ratings of somatic side effects and mood states at $0845 \mathrm{~h}$. To reduce the necessity of multiple needle sticks for multiple blood draws, an intravenous catheter was inserted into an antecubital vein at $0900 \mathrm{~h}$, and a baseline blood sample $(10 \mathrm{ml})$ was drawn at $0915 \mathrm{~h}(15$ min prior to drink administration). The viability of the intravenous catheter was maintained throughout the experimental day with a slow, steady saline drip. To standardized drink administration, a member of the research team mixed each of the different amino-acid formulations with water to a total volume of $8 \mathrm{oz}$ with the addition of $10 \mathrm{ml}$ of chocolate syrup (Bjork et al. 1999; Marsh et al. 2002; Weltzin et al. 1995; Young et al. 1985). The same individual read a standardized written script aloud to the participant and, at $0930 \mathrm{~h}$, administered of one of the five amino-acid formulations: (1) $50 \mathrm{~g} L$-tryptophan depletion (T-/ 50g); (2) 100g $L$-tryptophan depletion ( $\mathrm{T}-/ 100 \mathrm{~g}$ ); (3) $50 \mathrm{~g} L$ tryptophan loading (T+/50g); (4) 100g $L$-tryptophan loading ( $\mathrm{T}+/ 100 \mathrm{~g}$ ); or (5) $50 \mathrm{~g} L$-tryptophan balanced control formulation $(\mathrm{TB} / 50 \mathrm{~g})$. The composition of each mixture was based on Young and colleagues' formulations $(1985,1989)$ and is summarized in Table $1 . L$-cysteine and $L$ methionine were administered in capsules due to their aversive taste and smell.

Each participant consumed their respective amino-acid beverage within a 20-min period. No talking was allowed during drink administration; the staff member sat across the room from the participant and left the University Clinical Research Center following administration. Following drink administration, seven blood samples of $10 \mathrm{ml}$ each were drawn at: 1030, 1130, 1230, 1330, 1430, 1530, and 1630 hrs. At 1445 (approximately $5 \mathrm{~h}$ after drink consumption), participants completed their second assessment of somatic side effects and mood states for determining change from baseline assessment. Administration of this assessment was timed to correspond with previous assessments following $L$-tryptophan consumption (typically 4 to 6 hrs following drink consumption; e.g., Young et al. 1985, 1989). Participants remained awake in a supine position (with head elevated) and read or watched television throughout the day of testing. Room-temperature water was provided ad libitum. After collection of the final blood samples, the intravenous catheter was removed, vital signs were assessed, and a meal was provided at the hospital cafeteria.

\section{Biochemical Laboratory Procedures}

Blood samples were collected in $10 \mathrm{ml}$ tubes containing ethylene diamine tetra-acetic acid (EDTA; an anticoagulant), and plasma was isolated by centrifugation at $1968 \times g$ for 20 min and frozen at $-80^{\circ} \mathrm{C}$ until analysis. A $1 \mathrm{ml}$ portion of the isolated plasma was ultrafiltered by centrifugation $(1968 \times g$ for $20 \mathrm{~min})$ at room temperature using the Amicon Micropartition MPS-1 assembly (Amicon Bioseparations; Beverly, MA; Millipore Corporation; Burlington, $\mathrm{MA})$. Both the ultrafiltrate and the remaining parent plasma were stored at $-80^{\circ} \mathrm{C}$.

Three primary assays for $L$-tryptophan (Trp) and the competing amino acids (CAA) were conducted for this experiment: (1) [Free Trp], the unbound fraction of circulating plasma Trp; (2) [Total Trp], circulating Trp that is both free and albumin-bound; and (3) [CAA], the competing amino acids: valine, leucine, isoleucine, phenylalanine and tyrosine. The values for the individual [CAAs] were summed for calculation of the [Free Trp] / [CAA] and [Total Trp] / [CAA] ratios. [Free Trp] was determined in plasma ultrafiltrates using a modification (Bloxam and Warren, 1974) of a fluorimetric method (Denckla and Dewey, 1967), as described previously (Badawy and Evans, 1976). Plasma [Total Trp] and the [CAAs] were assayed using a rapid gas-chromatographic (GC) procedure. This method is based on a commercially available amino-acid analysis kit (the EZ:faast ${ }^{\mathrm{TM}}$ ) from Phenomenex, Ltd. (Macclesfield 
Cheshire, UK), which has been adapted for plasma amino-acid assays. In brief, details of this methodology include a Perkin Elmer State of the Art Clarus 500 GC, with FID and manual split injection; Zebron-AAA column $(10 \mathrm{~m} \times 0.25 \mathrm{~mm}$, Phenomenex, Inc.); 30 degrees oven temperature program (from $110^{\circ} \mathrm{C}$ to $320^{\circ} \mathrm{C}$ ) $320^{\circ} \mathrm{C}$ FID temperature; $250^{\circ} \mathrm{C}$ injector temperature; hydrogen carrier gas ( 8 psi: flow rate $1 \mathrm{ml} / \mathrm{min}$ ). An advantage of this methodology is that it requires no prior protein removal, relying instead on solid-phase extraction, which reduces processing time to $10 \mathrm{~min}$ per 2 samples and a GC runtime of $7 \mathrm{~min}$ per sample. Finally, standard methodologies were used to measure both plasma albumin (Doumas and Biggs, 1972) and the non-esterified fatty acids (NEFA; Mikac-Devic et al. 1973).

\section{Somatic Side Effect and Mood State Measures}

Two visual analog scales were used to assess somatic side effects and mood states, the Bodily Symptoms Scale (BSS; Cleare and Bond, 1995), and the Mood Rating Scale (MRS; Bond and Lader, 1974). The BSS is a 14-item scale composed of questions about common somatic symptoms (e.g., stomach ache). Participants rated each item by placing a single mark across a $100 \mathrm{~mm}$ line anchored on the left by the statement "no symptoms" and on the right by the statement "very strong symptoms." Similarly, the MRS is a 17-item visual analog scale used for rating current mood states. Participants rated each item by placing a mark across a $100 \mathrm{~mm}$ line anchored at each end by opposing mood states (e.g., happy - sad). All items on both scales were scored by measuring the distance between the leftmost anchor and the participant's mark on the line (in $\mathrm{mm}$ ). These self-report rating scales were previously found to be sensitive to subjective effects following consumption of a 100g amino-acid formulation (e.g., Cleare and Bond, 1995).

\section{Data Analyses}

Participant characteristics of the five groups were analyzed with one-way ANOVAs or twotailed independent or paired $t$-Tests for continuous variables (e.g., age) and two-tailed Chisquare tests for categorical variables (e.g., ethnicity). MANOVA results are reported in cases where the assumption of sphericity for ANOVA was not met. SPSS $\odot$ version 15.0 (SPSS, Inc., Chicago, IL) was used for all data analyses.

Biochemical Measures-Because the free Trp ratio has been suggested to be the best indicator of Trp bioavailability to the brain (Biggio et al. 1974; Moja et al. 1989; Van der Does, 2001), and due to space limitations, the omnibus analyses of variance (ANOVA) for depletion and loading comparisons are reported for the ratio of [Free Trp] / [CAA] only, with Bonferroni corrected follow-up tests at 4,5 , and $6 \mathrm{~h}$ following drink administration (i.e., typical measurement points in previous studies). The complete time-course of raw data for individual amino-acid assays is also reported.

Because there were no gender differences for any of the plasma measures of [Free Trp], [Total Trp], [CAA], or the respective bioavailability ratios, gender was not included as a factor in any analyses. Because both non-esterified fatty acids (NEFA) and albumin affect the availability of free Trp and these measures differed significantly between groups (see Results, below), additional one-way analyses of covariance (ANCOVA) were conducted using NEFA and albumin as covariates for comparisons of the $50 \mathrm{~g}$ and $100 \mathrm{~g}$ formulations at 4,5 , and $6 \mathrm{hrs}$.

Mood State and Somatic Symptom Measures-In a preliminary examination of the self-report data, two separate principal components analyses were conducted to determine the number of uncorrelated components within the Bodily Symptoms Scale (BSS) and the Mood Rating Scale (MRS) self-report measures. This procedure was done to reduce the original larger set of variables within each measure to a smaller set of factors that represent the information 
found in the original variables. Furthermore, the reduction of the number of comparisons within each measure facilitates interpretation of subsequent analytical comparisons. The 14 items of the BSS loaded onto 2 factors, and the 17 items of the MRS loaded onto 4 factors. A mean score was calculated from the items within each factor and used for the final analyses.

Using the resulting factors from each measure, separate between-within ANOVAs were conducted for the MRS (i.e., mood states) and BSS (i.e., somatic symptoms) scores. Analyses of both measures were used to compare the morning and afternoon self-report scores for the $50 \mathrm{~g}$ and $100 \mathrm{~g}$ depletion, and the $50 \mathrm{~g}$ and $100 \mathrm{~g}$ loading. These specific comparisons were based on previous experience that indicated loading and depletion formulations would be expected to produce different symptomatology in both mood and somatic symptoms (Marsh et al., 2002).

\section{Results}

Participants

The 112 participants who completed the study included equal numbers of men and women in each of the five amino-acid drink groups: T- $/ 50 \mathrm{~g}(n=24) ; \mathrm{T}+/ 50 \mathrm{~g}(n=24)$; TB/50g $(n=24)$; $\mathrm{T}-/ 100 \mathrm{~g}(n=20)$; and $\mathrm{T}+/ 100 \mathrm{~g}(n=20)$. There was no significant gender or group difference in age, education, cigarette/alcohol use, or ethnicity. A summary of the characteristics of the participants who completed the study appears in Table 2 . There were also no significant gender differences for height (means \pm SEM; men: $172.1 \pm 9.4 \mathrm{~cm}$; women: $169.8 \pm 10.9 \mathrm{~cm}$ ), weight (men: $70.7 \pm 9.6 \mathrm{~kg}$; women: $67.5 \pm 10.2 \mathrm{~kg}$ ), or body mass index (men: $23.4 \pm 2.9 \mathrm{~kg} / \mathrm{m}^{2}$, range 18-30; women: $23.8 \pm 2.6 \mathrm{~kg} / \mathrm{m}^{2}$, range 20-29).

A total of 124 adults were originally screened for this study. Based on inclusion/exclusion criteria, three men were excluded because of a positive drug screen (cocaine, amphetamines, and/or THC), and one woman was excluded because of self-reported use of zolpidem tartrate (Ambien $\left({ }^{\circledR}\right)$. Of the remaining 120 participants, eight women failed to complete the study and were excluded from final statistical analyses; seven withdrew because of emesis occurring shortly after ingesting the amino acid beverage and one withdrew because she could not completely consume the drink due to discomfort. Four of these women were in the T- $/ 100 \mathrm{~g}$ group, and four were in the $\mathrm{T}+/ 100 \mathrm{~g}$ group. Comparing the five drink conditions, dropout rates differed within the entire sample $(N=120$; Chi-Square $4=12.9 ; p=.012)$ and among women only $(n=64$; Chi-Square $4=11.8 ; p=.019)$ across the experimental conditions.

\section{Biochemical Analyses of Plasma L-tryptophan Measures}

The time-course effects of each of the $L$-tryptophan (Trp) manipulations across $7 \mathrm{~h}$ of measurements following the amino-acid administration are presented for the individual variables of Free Trp, Total Trp, and the sum of the competing amino acids (CAAs) in Figure 1. These comparisons of the $50 \mathrm{~g}$ and $100 \mathrm{~g}$ beverages are presented separately for the $\mathrm{T}-$ (panels a, c, and e) and T+ (panels b, d, and f) conditions. Statistical analyses of peak effects are reported below both as the percent change from the baseline pre-drink measure and as raw data. Due to space limitations, the statistical analyses of the effects of the $50 \mathrm{~g}$ and $100 \mathrm{~g}$ depletion and loading are presented for the [Free Trp] / [CAA] ratio only. However, for reference purposes, raw data for all variables are provided in Table 3.

\section{Omnibus Analyses}

L-Tryptophan Depletion-The overall between-within analyses of variance (ANOVA) showed that both the $50 \mathrm{~g}$ and $100 \mathrm{~g}$ depletion formulations produced robust reductions of the plasma [Free Trp] / [CAA] ratio across time, although the maximal effects were not equivalent (Figure 2, panel a). This was indicated by an interaction of Formulation Size $\times$ Time $(2 \times 7$, 
percent change from baseline: $F_{6,37}=3.23, p=.012 ; 2 \times 8$, raw values: $F_{7,36}=4.34, p=$. 001). Follow-up analyses of the maximal differences in the effects of the $50 \mathrm{~g}$ and $100 \mathrm{~g}$ formulations at 4, 5, and $6 \mathrm{~h}$, and the time-course effects for the [Free Trp] / [CAA] ratio are detailed below.

L-Tryptophan Loading-Parallel analyses of the $50 \mathrm{~g}$ and $100 \mathrm{~g}$ loading formulations produced robust increases of the plasma [Free Trp] / [CAA] ratio across time, although the maximal changes across time were not equivalent (Figure 2, panel b). This was indicated by an interaction of Formulation Size $\times$ Time (percent change from baseline: $F_{6,37}=4.21, p=$. 003 ; raw values: $F_{7,36}=3.63, p=.005$ ) in the between-within analyses of variance. Followup analyses of the maximal differences in the effects of the $50 \mathrm{~g}$ and $100 \mathrm{~g}$ formulations at 4,5 , and $6 \mathrm{~h}$, and the time-course effects for the [Free Trp] / [CAA] ratio are detailed below.

\section{Maximal Effects of the $50 \mathrm{~g}$ and $100 \mathrm{~g}$ Formulations Relative to Baseline}

This first set of follow-up analyses was conducted to confirm expectations that both the $50 \mathrm{~g}$ and the $100 \mathrm{~g}$ depletion and loading beverages resulted in significant changes in the plasma [Free Trp] / [CAA] ratio. Measurements of raw data from at 4,5 , and $6 \mathrm{~h}$ following consumption of the amino-acid beverages were each compared to the pre-drink baseline measurements $(-0.25 \mathrm{~h})$ for both sizes of depletion and loading formulations. The analyses of the difference from baseline for the [Free Trp] / [CAA] ratio at the three time points is shown below as the percent change.

L-Tryptophan Depletion-At $4 \mathrm{~h}$ following Trp depletion, the maximal decrease of the [Free Trp] / [CAA] ratio was $-89.0 \%$ following the $50 \mathrm{~g}$ formulation and $-95.7 \%$ following the 100g formulation (Figure 2a). Comparing the typical measurement points of 4,5 , and $6 \mathrm{~h}$ post-drink to the baseline measurements, there was significant decrease of the [Free Trp] / [CAA] ratio for both sizes of depletion formulations at 4,5 , and $6 \mathrm{~h}(\mathrm{~T}+/ 50 \mathrm{~g}: p \leq .001 ; \mathrm{T}+/$ 100g: $p \leq .001$ ) following drink consumption.

L-Tryptophan Loading-The maximal increase of the [Free Trp] / [CAA] ratio was $+570 \%$ following the $50 \mathrm{~g}$ drink and $+372 \%$ following the $100 \mathrm{~g}$ drink (Figure $2 \mathrm{~b}$ ). Again, comparing the typical measurement points of 4,5 , and $6 \mathrm{~h}$ post-drink to the baseline measurements, there was a significant increase of the [Free Trp] / [CAA] ratio for both the $50 \mathrm{~g}$ and $100 \mathrm{~g}$ loading formulations at 4, 5, and $6 \mathrm{~h}(\mathrm{~T}+/ 50 \mathrm{~g}: p \leq .001 ; \mathrm{T}+100 \mathrm{~g}: p \leq .001)$ following drink consumption.

\section{Peak Effects Comparison of $50 \mathrm{~g}$ versus $100 \mathrm{~g}$ Formulations}

The following set of analyses was conducted to directly compare the effectiveness of the $50 \mathrm{~g}$ and the 100g depletion and loading formulations for changing plasma levels of the [Free Trp] / [CAA] ratio at 4,5 , and $6 \mathrm{~h}$ following beverage consumption. The analyses below first compare the effects of the $50 \mathrm{~g}$ and $100 \mathrm{~g}$ depletion and loading beverages as the percent change from baseline at each measurement point (similar to previous research) and then compare effects in parallel analyses using the original raw data for both the depletion and loading.

L-Tryptophan Depletion-At the peak effects following beverage consumption, follow-up analyses indicated that the $100 \mathrm{~g}$ formulation depleted the bioavailability of Trp (i.e., [Free Trp] / [CAA] ratio) more than the 50g formulation. Follow-up comparisons at 4, 5, and $6 \mathrm{~h}$ after depletion showed that the percent change from baseline of the $100 \mathrm{~g}$ beverage was significantly larger than the $50 \mathrm{~g}$ beverage at all three time points $(p \leq 001)$. While these differences were reduced after taking NEFA and albumin concentrations into account using separate ANCOVAs at the same 4, 5, and $6 \mathrm{~h}$ time points, the $100 \mathrm{~g}$ depletion formulation was still significantly more effective for reducing the [Free Trp] / [CAA] ratio than the 50g 
formulation at the $4(p=.006)$ and $5(p=.022) \mathrm{h}$ post-drink measurements, but not at the $6 \mathrm{~h}$ measurement $(p=.815)$.

The parallel analyses using the raw data (i.e., not calculated as a percent of baseline) of the [Free Trp] / [CAA] ratio (Figure 2a) at 4, 5, and $6 \mathrm{~h}$ following drink consumption showed the depletion effects of the $100 \mathrm{~g}$ formulation relative to the $50 \mathrm{~g}$ were even larger (all time points, $p<.001$ ) than the effects found in the percent change from baseline analyses (above). These differences remained significant after taking the potential influence of NEFA and albumin into account (all time points, $p<.001$ ).

L-Tryptophan Loading-Using values as a percent change from baseline, follow-up comparisons showed the 50g loading formulation increased the bioavailability of Trp (i.e., [Free Trp] / [CAA] ratio) more than the $100 \mathrm{~g}$ formulation at 4 and $5 \mathrm{~h}$ following beverage consumption $(p=.004 ; p=.024$ respectively), but not at $6 \mathrm{~h}(p=.441)$. However, after adjusting for the potential influence of NEFA and albumin concentrations, there were no significant differences at any of the three time points $(p=.291$ to .738$)$.

Similar to the depletion analyses above, parallel analyses were conducted using the raw data of the [Free Trp] / [CAA] ratio (Figure 2b). These comparisons showed there were no significant differences between the loading effects of the $100 \mathrm{~g}$ and the $50 \mathrm{~g}$ formulations at 4 , 5 , and $6 \mathrm{~h}$ following drink consumption $(p=.081$ to .847$)$. After taking the potential influence of NEFA and albumin into account, a significant difference between the two loading formulations was found at $6 \mathrm{~h}$ post-drink $(p<.014)$, but not at 4 or $5 \mathrm{~h}(p<.515 ; p<.398$, respectively).

\section{Changes Produced by $50 \mathrm{~g}$ Depletion and Loading Relative to $50 \mathrm{~g}$ Balanced Control}

Comparisons of both the $50 \mathrm{~g}$ depletion and loading formulations produced the expected differences in plasma measures relative to the $\mathrm{TB} / 50 \mathrm{~g}$ balanced control formulation (see Table 3). Compared to the TB/50g, the T- $150 \mathrm{~g}$ manipulation produced significant depletion of the [Free Trp] / [CAA] ratio at the 4,5 , and $6 \mathrm{~h}(p \leq .001)$ measurements. Similarly, the T+/50g formulation produced a significant increase of the [Free Trp] / [CAA] ratio compared to the $\mathrm{TB} / 50 \mathrm{~g}$ at the 4,5 , and $6 \mathrm{~h}(p \leq .001)$ measurements.

\section{L-tryptophan Manipulation Effects on Mood and Somatic Symptom Ratings}

Prior to our final analyses of mood and somatic symptom ratings, a factor analysis was conducted for both the Mood Rating Scale (MRS) and the Bodily Symptoms Scale (BSS). This analysis of MRS ratings revealed 4 factors within the 17 self-rated items of mood state. A similar analysis of BSS ratings revealed 2 factors within the 14 self-rated items of somatic symptoms.

Mood Rating Scale (MRS)—Factor 1 included 6 items: Amicable/Antagonistic, Tranquil/ Troubled, Competent/Incompetent, Not Nauseated/Nauseated, Clearheaded/Confused, and Clear Headed/Mentally Slow. Factor 2 included 7 items: Interested/Bored, Attentive/Dreamy, Alert/Drowsy, Happy/Sad, Strong/Feeble, Well Coordinated/Clumsy, Contented/

Discontented. Factor 3 included 2 items: Gregarious/Withdrawn and Energetic/Lethargic, and Factor 4 included 2 items: Calm/Excited and Relaxed/Tense. The 50g and 100g comparisons were conducted separately for depletion and loading conditions using two $2 \times 2 \times 4$ ANOVAs (Formulation Size $\times$ Time $\times$ MRS Factor).

L-tryptophan Depletion: Comparisons of the two depletion formulations ( $\mathrm{T}-150 \mathrm{~g}$ and $\mathrm{T}-$ I $100 \mathrm{~g}$ ) showed that negative self ratings of mood increased across time (AM to PM) as a function of the mood Factor (Time $\times$ MRS Factor: $F_{3,42}=10.40, p<.001$ ). There were no differences 
between the two sizes of depletion formulations, which indicates that depletion in general increased negative mood ratings from morning to afternoon for Factors $1(p=.001)$ and 2 $\left(t_{43}=3.83, p<.001\right)$, but remained unchanged for Factors 3 and $4(p>.05)$. There was no main effect or interaction indicating any formulation size differences.

L-tryptophan Loading: Comparisons of the two loading formulations ( $\mathrm{T}+/ 50 \mathrm{~g}$ and $\mathrm{T}+/ 100 \mathrm{~g}$ ) indicated that self-report ratings of mood became more negative across time dependent on the size of the formulation (Formulation Size $\times$ Time: $F_{1,42}=9.05, p=.004$ ) and dependent on the mood Factor (MRS Factor $\times$ Time: $F_{3,40}=17.90, p<.001$ ). Regardless of the MRS Factor, self-ratings of mood state following consumption of the $100 \mathrm{~g}$ formulation $(p=.001)$ became more negative from morning to afternoon ratings while ratings following the $50 \mathrm{~g}$ formulation did not $(p>.05)$. Regardless of drink size, consumption of the loading drinks was followed by increased negative mood ratings for items on MRS Factors $1(p=.013), 2(p<.001)$, and 3 $(p<.001)$, but ratings of items on Factor 4 showed improved ratings $(p=.030)$. There were no other significant interactions.

Bodily Symptoms Scale (BSS)—Factor 1 included 11 items: Sweating, Fast Heart, Shaking, Dizziness, Irritability, Nausea, Anxiety, Depression, Tension, Headache, and Loss of Appetite. Factor 2 included 3 items: Loss of Concentration, Tiredness, and Stomach Ache. The $50 \mathrm{~g}$ and $100 \mathrm{~g}$ comparisons were conducted separately for depletion and loading conditions using two $2 \times 2 \times 2$ ANOVAs (Formulation Size $\times$ Time $\times$ BSS Factor).

L-tryptophan Depletion: Comparisons of the two depletion formulations (T- $/ 50 \mathrm{~g}$ and $\mathrm{T}-$ / $100 \mathrm{~g}$ ) showed that negative self ratings of somatic symptoms increased after depletion (main effect of Time: $F_{1,42}=8.34, p=.006$ ) and that BSS Factor 2 resulted in significantly higher ratings of somatic symptoms relative to BSS Factor $1\left(F_{1,42}=31.85, p<.001\right)$. There were no differences between the two drink sizes, and there were no significant interactions among Drink Size, BSS Factor, and Time.

L-tryptophan Loading: Comparisons of the two loading formulations ( $\mathrm{T}+/ 50 \mathrm{~g}$ and $\mathrm{T}+/ 100 \mathrm{~g}$ ) indicated that self-report ratings of negative somatic symptoms increased across Time (AM to PM ratings) as a function of the size of the formulation (Formulation Size $\times$ Time: $F_{1,42}=$ 7.04, $p=.011$ ) and as a function of BSS Factor (Time $\times$ Factor: $F_{1,42}=4.74, p=.035$ ). Ratings of somatic symptoms were significantly poorer over time following the $100 \mathrm{~g}$ formulation $(p$ $=.001$ ) relative to the 50g formulation $(p=.021)$, and Factor 1 afternoon (post drink) ratings showed a $149 \%$ increase in the perception of negative side effects compared to morning ratings $(p<.000)$ relative to a $125 \%$ increase for Factor 2 ratings from AM to PM $(p<.000)$.

\section{Discussion}

The primary aims of this study were to characterize and compare the peak effects and comprehensive time course of changes in the peripheral markers of central serotonin (5-HT) synthesis following 50g and 100g $L$-tryptophan (Trp) depletion and loading manipulations in healthy adults. The primary questions being tested by our analyses were whether the $100 \mathrm{~g}$ depletion and loading formulations would produce significantly greater effects than the $50 \mathrm{~g}$ formulations for changing bioavailability markers of 5-HT, both across time and at their peak effects, and whether the two $50 \mathrm{~g}$ formulations would reduce negative somatic symptoms, while maintaining mood state changes compared to the two $100 \mathrm{~g}$ formulations.

\section{L-tryptophan Manipulations - Changes from Baseline and Peaks Effects Comparison}

As expected, both the 50g and $100 \mathrm{~g}$ amino-acid depletion and loading formulations produced robust changes in the [Free Trp] / [CAA] ratio (the primary bioavailability marker; Biggio et 
al. 1974; Moja et al. 1989; Van der Does, 2001) relative to their respective baseline (pre-drink) measurements, and the $100 \mathrm{~g}$ depletion was found to be significantly more effective than the $50 \mathrm{~g}$ formulation. Relative to the pre-drink measure, the maximal loading was $372 \%$ following the $100 \mathrm{~g}$ formulation and $+570 \%$ following the $50 \mathrm{~g}$ formulation, and maximal depletion following the $100 \mathrm{~g}$ and $50 \mathrm{~g}$ formulations was $-95.7 \%$ and $-89.0 \%$, respectively. While the extent of Trp depletion can vary greatly between studies, these depletion values are consistent with previous reports of $-85 \%$ to $-92 \%$ depletion of the [Free Trp] / [CAA] ratio following $100 \mathrm{~g}$ formulations administered in other studies (e.g., Kaye et al. 2000; Weltzin et al. 1995). A direct comparison of the two sizes showed that the $100 \mathrm{~g}$ depletion produced significantly greater reductions of the [Free Trp] / [CAA] ratio compared to the 50g formulation. This was evident at 4, 5, and $6 \mathrm{~h}$ after the manipulation, which are the time points that have typically been assessed in previous studies (e.g., Hughes et al. 2002, 2003), with the majority of those assessments conducted at $5 \mathrm{~h}$ following manipulations (e.g., Bjork et al. 1999; Cleare and Bond, 1995; Luciana et al. 2001; Marsh et al. 2002).

This difference in 5-HT synthesis is likely because the rate-limiting step of the synthesis process is Trp hydroxylase, which is unsaturated and exhibits an almost linear relationship with its Trp substrate. Therefore, it is almost certain that the higher [Free Trp] / [CAA] ratio observed after the $50 \mathrm{~g}$ depletion (relative to the $100 \mathrm{~g}$ ) reflects at least twice as high a rate of entry of Trp into the brain. This, in turn, would then be likely to produce at least twice as high a rate of 5-HT synthesis, similar to differences we found at 4,5 , and $6 \mathrm{~h}$ following manipulations.

While the analyses of the percent change from baseline is a useful variable for determining changes from baseline and for comparison with results of previous studies, the raw data are better indicators of substrate bioavailability when making direct comparisons between these different size formulations. As found in the direct comparison of the two sizes of formulations using the percent change from baseline, when analyzing the raw data (i.e. [Free Trp] / [CAA] ratio) the $100 \mathrm{~g}$ formulation showed a significantly larger depletion effect relative to the $50 \mathrm{~g}$ formulation. Conversely, our parallel analysis of the two loading formulations showed that the effectiveness for producing change in the [Free Trp] / [CAA] ratio was not different until the potential influence of the non-esterified fatty acids (NEFA) and albumin was taken into account. This influence showed that the effect of the $100 \mathrm{~g}$ formulation may have actually been greater than the $50 \mathrm{~g}$ at the $6 \mathrm{~h}$ post-drink measurement (but not the 4 or $5 \mathrm{~h}$ time points). Both albumin and NEFA are important variables, because albumin-bound Trp cannot cross the blood-brain barrier, and NEFA is involved in freeing Trp from its albumin-bound state. Consequently, because we found group differences in both of these variables, it was important to determine how these measures may have influenced our results. Because the albumin-bound Trp is not available for transport into the brain, the [Total Trp] / [CAA] ratio is most likely a poorer representative of the rate of 5-HT synthesis compared to the [Free Trp] / [CAA] ratio.

Another consideration that likely explains the differential changes we found in our analyses of the bioavailability ratio of [Free Trp] / [CAA] following the 50g and 100g formulations is that the $50 \mathrm{~g}$ formulation contained half the amount of the CAAs (see Table 1), which produced 35$37 \%$ lower concentrations of plasma CAAs than the 100g (regardless of depletion or loading; see Figure 1e and 1f). Therefore, because of the larger concentration of plasma Free Trp (Figure 1a) in the 50g depletion relative to the smaller amount of CAAs, the [Free Trp] / [CAA] ratio would be larger the $100 \mathrm{~g}$ producing less depletion over time (Figure $2 \mathrm{a}$ ). The converse would then be true for the loading conditions; the $50 \mathrm{~g}$ loading formulation contained half the amount of Trp and half the amount of CAAs than the 100g, which would result in similar [Free Trp] / [CAA] ratios (Figure 2b) across time. However, the potential functional significance of such differences in serotonin synthesis cannot be appraised based on these data and must therefore await the outcome of studies assessing mood, cognition, and other behaviors in different clinical populations. 
In an imaging study designed to directly examine changes in brain 5-HT synthesis in humans following a 100g depletion formulation, Nishizawa and colleagues (1997) conducted a positron emission tomography (PET) scan before and again $5 \mathrm{~h}$ after $L$-tryptophan manipulations. In general, they found that 5-HT synthesis was relatively uniform across the different brain areas studied, irrespective of the differences in the density of innervation. They also found that at 5 $\mathrm{h}$ following peripheral Trp depletion, brain 5-HT synthesis was significantly depleted and that this effect in the brain was somewhat greater than the effect on plasma free Trp. However, having used a single pre- and post-drink measurement, what Nishizawa and colleagues' study does not determine is the time point of the peak changes in brain 5-HT or the duration of effects, which are considerations that would likely be important to protocols investigating depletion or loading effects across longer periods of time.

Similarly, our findings do not indicate the time of peak changes in levels of brain 5-HT, the duration of the sustained effects on brain 5-HT synthesis, or whether there are brain mechanisms that may compensate for changes in substrate availability. The onset of the peak change and the duration of significant changes in brain 5-HT concentrations and function following Trp depletion and loading is speculative since this information can only be inferred from studies that have concurrently measured both the peripheral (e.g., plasma Trp) and central indicators (e.g., cerebrospinal fluid [or CSF] Trp or the primary metabolite of 5-HT, 5hydroxyindoleacetic acid) of 5-HT synthesis and degradation (turnover). For example, two previous studies have provided evidence that central measures reach their nadir approximately two hours after the nadir of the peripheral measures for both the $50 \mathrm{~g}$ (Williams et al. 1999) and 100g (Carpenter et al. 1998) depletion formulations. This implies that maximal changes in brain 5-HT likely occur within this two hour time frame; however, the question of the duration of changes remains unanswered since the time course of sampling in these studies did not extend far enough to determine the duration of significant effects for either peripheral or central measures. Therefore, while methodologies for manipulating peripheral indicators of brain 5HT synthesis are common and have been related to numerous psychopathologies and other physical problems, there are additional factors to consider when drawing conclusions from studies using this methodology regardless of the size of the formulation used for Trp manipulations.

There are several important methodological contributions from the current study in addition to our analytical comparisons. One such contribution is the comprehensive presentation of data across 7 hourly measurements for the typical variables measured following Trp manipulations. For example, as can be observed in Table 3, the [Free Trp] / [CAA] ratio for both the 50g and $100 \mathrm{~g}$ depletion formulations showed peak effectiveness at $4 \mathrm{~h}$ and these effects continued to be depleted by $-79 \%$ and $-82 \%$ (respectively) from the baseline values at the final $7 \mathrm{~h}$ measurement. For the loading formulations, there was a slight difference in the onset of the peak effects where the maximum increase following the $50 \mathrm{~g}$ formulation was observed at $3 \mathrm{~h}$ while the maximum increase of the $100 \mathrm{~g}$ formulation was observed at $4 \mathrm{~h}$ following $\operatorname{Trp}$ manipulations, although the loading effects of both manipulations continued to be elevated by $255 \%$ to $310 \%$ over baseline values at the final $7 \mathrm{~h}$ measurement (100g and $50 \mathrm{~g}$, respectively). These observations of the time-course data illustrate how this information can serve as a valuable resource for planning future studies. Not only do these findings provide some guidance for future research as to when the peak changes of these peripheral measures occur, but they also provide an indication of the magnitude and duration of the effects on plasma measures of Trp bioavailability following both sizes of the depletion and loading formulations.

\section{L-tryptophan Manipulations - Effects on Mood States, Somatic Symptoms, and Attrition}

For the depletion conditions, while there were no differences between the $50 \mathrm{~g}$ and $100 \mathrm{~g}$ formulations in terms of somatic symptoms or mood, we did find the expected increases in 
negative mood states irrespective of the size of the drink consumed. Both sizes of the formulation produced similar increases in the ratings included in Factors 1 and 2 of the Mood Rating Scale, as well as similar increases in somatic symptom ratings on the Bodily Symptom Scale, although, because we tested a normal control sample that is often less responsive to these manipulations, the lack of mood differences between the two sizes of depletion formulations is difficult to interpret. While less commonly used, in the loading conditions we found that the $100 \mathrm{~g}$ formulation resulted in more negative reports of mood states, while the $50 \mathrm{~g}$ formulation did not, and the $100 \mathrm{~g}$ formulation produced higher ratings of negative somatic symptoms than the $50 \mathrm{~g}$ formulation.

Previous research using the L-tryptophan manipulation methodology has varied in their reports of mood and somatic symptom effects; however, a sizeable number of studies have indicated that undesirable somatic symptoms appeared to impact attrition rates of their study participants (e.g., Allen et al. 2006; Booij et al. 2005; Delgado et al. 1990; Klaassen et al. 1999; Marsh et al. 2002; Moeller et al. 1996; Schmitt et al. 2000; Smith et al. 1986). In the current study, while all participants in both of the $50 \mathrm{~g}$ conditions remained in the study, we experienced attrition of 8 women as the result of negative somatic symptoms (i.e., nausea and emesis), and all were in the $100 \mathrm{~g}$ conditions ( 4 depletion and 4 loading). Given these observable physical effects, it is quite conceivable that those who discontinued the study may have endorsed more negative somatic side effects and mood ratings than those who completed the study. While there are certainly unknown factors that influence side effects following Trp manipulations, it is also possible that the current results of mood and somatic symptom ratings may be biased, underestimating the true effects of the $100 \mathrm{~g}$ formulations.

\section{Conclusions}

The data from this study provide valuable information about the effects of the size of Trp depletion and loading formulations on plasma indicators of 5-HT synthesis. We found that even when the traditional $100 \mathrm{~g}$ dose is halved to $50 \mathrm{~g}$ there was still a significantly large depletion effect on the plasma indicators of 5-HT synthesis compared to baseline measures. In the depletion condition, a $-88 \%$ and $-96 \%$ reduction from baseline for the $50 \mathrm{~g}$ and $100 \mathrm{~g}$ formulations was observed. However, the doses were not equally effective and, in fact, the $100 \mathrm{~g}$ formulation produced significantly larger depletion than the $50 \mathrm{~g}$ formulation. Increases of $+570 \%$ and $+372 \%$ were observed following the $50 \mathrm{~g}$ and $100 \mathrm{~g}$ loading formulations, which were not significantly different. Besides the effects on the plasma measures, the two sizes of formulations differed in attrition, with a significantly higher loss of participants due to somatic side effects in the two $100 \mathrm{~g}$ conditions. Furthermore, among the participants who were able to complete the study, we found that increases in negative mood ratings were not different between the $50 \mathrm{~g}$ and $100 \mathrm{~g}$ depletion formulations, but that negative mood ratings increased from morning to afternoon following depletion in general. Finally, we have provided a comprehensive presentation of multiple plasma markers for 5-HT synthesis across a 7 hour time-course. Taken together these findings are useful for informing investigators of the relative effects one may expect following the use of the $100 \mathrm{~g}$ or $50 \mathrm{~g}$ Trp manipulation.

\section{Acknowledgments}

Dr. Dougherty gratefully acknowledges support from the William \& Marguerite Wurzbach Distinguished Professorship. We thank Michael A. Dawes, M.D., (Psychiatry Department, The University of Texas Health Science Center at San Antonio) for his review and editorial contributions to this manuscript, as well as Karen Klein, MA, ELS, (Research Support Core, Wake Forest University Health Sciences) for her editorial contributions.

While the authors Dougherty, Marsh-Richard, Mathias, and Addicott were affiliated with The University of Texas Health Science Center at Houston during the data collection for this study, Drs. Dougherty, Marsh-Richard, and Mathias have since relocated to The University of Texas Health Science Center at San Antonio. Ms. Addicott has relocated to the Wake Forest University School of Medicine. 
This research was sponsored by grants from the National Institutes of Health (R01-AA012046, R01-AA014988, and T32-AA07565), and a Wellcome Trust grant. The original article was published in Psychopharmacology, 198, 431445. The original publication is available at springerlink.com

\section{References}

Allen PP, Cleare AJ, Lee F, Fusar-Poli P, Tunstall N, Fu CHY, Brammer MJ, McGuire PK. Effect of acute tryptophan depletion on pre-frontal engagement. Psychopharmacology (Berl) 2006;187:486497. [PubMed: 16823591]

Badawy AA-B, Evans M. Animal liver tryptophan pyrrolases - Absence of apoenzyme and of hormonal induction mechanism from species sensitive to tryptophan toxicity. Biochem J 1976;158:79-88. [PubMed: 962891]

Biggio G, Fadda D, Fanni P, Tagliamonte A, Gessa GL. Rapid depletion of serum tryptophan, brain tryptophan, serotonin and 5-hydroxyindoleacetic acid by a tryptophan-free diet. Life Sci 1974;14:1321-1329. [PubMed: 4823644]

Bjork JM, Dougherty DM, Moeller FG, Cherek DR, Swann AC. The effects of tryptophan depletion and loading on laboratory aggression in men: Time course and a food-restricted control. Psychopharmacology (Berl) 1999;142:24-30. [PubMed: 10102779]

Bjork JM, Dougherty DM, Moeller FG, Swann AC. Differential behavioral effects of plasma tryptophan depletion and loading in aggressive and nonaggressive men. Neuropsychopharmacology 2000;22:357-369. [PubMed: 10700655]

Bloxam DL, Warren WH. Error in the determination of tryptophan by the method of Denckla and Dewey. A revised procedure. Anal Biochem 1974;60:621-625. [PubMed: 4844574]

Bond A, Lader MH. The use of analogue scales in rating subjective feelings. British J Med Psychology 1974;47:211-218.

Booij L, van der Does AJ, Haffmans PM, Riedel WJ. Acute tryptophan depletion as a model of depressive relapse: Behavioural specificity and ethical considerations. J Affect Disord 2005;86:305-311. [PubMed: 15935252]

Carlsson A, Lindqvist M. Dependence of 5-HT and catecholamine synthesis on concentrations of precursor amino acids in rat brain. Naunyn-Schmiedeberg's Arch Pharmacol 1978;303:157-164.

Carpenter LL, Anderson GA, Pelton GH, Gudin JA, Kirwin PDS, Price LH, Heninger GR, McDougle CJ. Tryptophan depletion during continuous CSF sampling in healthy human subjects. Neuropsychopharmacology 1998;19:26-35. [PubMed: 9608574]

Cleare AJ, Bond AJ. The effect of tryptophan depletion and enhancement on subjective and behavioral aggression in normal male subjects. Psychopharmacology (Berl) 1995;118:72-81. [PubMed: 7597125]

Delgado PL, Charney DS, Price LH, Aghajanian GK, Landis H, Heninger GR. Serotonin function and the mechanism of antidepressant action. Arch Gen Psychiatry 1990;47:411-418. [PubMed: 2184795]

Denckla WD, Dewey HK. The determination of tryptophan in plasma, liver, and urine. J Lab Clin Med 1967;69:160-169. [PubMed: 6018066]

Dierks T, Barta S, Demisch L, Schmeck K, Englert E, Kewitz A, Maurer K, Poustka F. Intensity dependence of auditory evoked potentials (AEPs) as biological marker for cerebral serotonin levels: Effects of tryptophan depletion in healthy subjects. J Psychopharmacol 1999;146:101-107.

Dougherty DM, Marsh DM, Mathias CW, Dawes MA, Bradley DM, Morgan CJ, Badawy AA. The effects of alcohol on laboratory-measured impulsivity after L-Tryptophan depletion or loading. Psychopharmacology (Berl) 2007;193:137-150. [PubMed: 17377773]

Doumas, BT.; Biggs, HT. Determination of serum albumin. In: Cooper, GR., editor. Standard Methods in Clinical Chemistry. Vol. 7. NY: Academic Press; 1972. p. 175-178.

Ellenbogen MA, Young SN, Dean P, Palmour RM, Benkelfat C. Mood response to acute tryptophan depletion in healthy volunteers: Sex differences and temporal stability. Neuropsychopharmacology 1996;15:465-474. [PubMed: 8914119]

Fernstrom JD. Role of precursor availability in control of monoamine biosynthesis in brain. Physiol Rev 1983;63:484-546. [PubMed: 6132421] 
First, MB.; Gibbon, M.; Spitzer, RL.; Williams, JBW.; Benjamin, L. Structured Clinical Interview for DSM-IV Axis II Personality Disorders (SCID-II). New York: Biometrics Research Department, New York State Psychiatric Institute; 1997.

First, MB.; Spitzer, R.; Gibbon, M.; Williams, JBW. Structured Clinical Interview for DSM-IV-TR Axis I Disorders, Research Version, Non-patient Edition (SCID-I/NP). New York: Biometrics Research, New York State Psychiatric Institute; 2001.

Gallagher P, Massey AE, Young AH, McAllister-Williams RH. Effects of acute tryptophan depletion on executive function in healthy male volunteers. BMC Psychiatry. 2003

Gessa GL, Biggio G, Fadda F, Corsini GU, Tagliamonte A. Effect of the oral administration of tryptophanfree amino acid mixtures on serum tryptophan, brain tryptophan and serotonin metabolism. J Neurochem 1974;22:869-870. [PubMed: 4407107]

Hughes JH, Dunne F, Young AH. Effects of acute tryptophan depletion on mood and suicidal ideation in bipolar patients symptomatically stable on lithium. Br J Psychiatry 2000;177:447-451. [PubMed: 11059999]

Hughes JH, Gallagher P, Young AH. Effects of acute tryptophan depletion on cognitive function in euthymic bipolar patients. Eur Neuropsychopharmacol 2002;12:123-128. [PubMed: 11872328]

Hughes JH, Gallagher P, Stewart ME, Matthews D, Kelly TP, Young AH. Effects of acute tryptophan depletion on neuropsychological function. J Psychopharmacol 2003;17:300-309. [PubMed: 14513922]

Hussain AM, Mitra AK. Effect of aging on tryptophan hydroxylase in rat brain: Implications on serotonin level. Drug Metab Dispos 2000;28:1038-1042. [PubMed: 10950846]

Kaye WH, Gendall KA, Fernstrom MH, Fernstrom JD, McConaha CW, Weltzin TE. Effects of acute tryptophan depletion on mood in Bulimia Nervosa. Biol Psychiatry 2000;47:151-157. [PubMed: 10664832]

Klaassen T, Riedel WJ, van Someren A, Deutz NE, Honig A, van Praag HM. Mood effects of 24-hour tryptophan depletion in healthy first-degree relatives of patients with affective disorders. Biol Psychiatry 1999;46:489-497. [PubMed: 10459398]

Knott VJ, Howson AL, Perugini M, Raindran AV, Young SN. The effect of acute tryptophan depletion and fenfluramine on quantitative EEG and mood in healthy male subjects. Biol Psychiatry 1999;46:229-238. [PubMed: 10418698]

Luciana M, Burgund ED, Berman M, Hanson KL. Effects of tryptophan loading on verbal, spatial and affective working memory functions in healthy adults. J Psychopharmacol 2001;15:219-230. [PubMed: 11769814]

Marsh DM, Dougherty DM, Moeller FG, Swann AC, Spiga R. Laboratory-measured aggressive behavior of women: Acute tryptophan depletion and augmentation. Neuropsychopharmacology 2002;26:660671. [PubMed: 11927191]

Mikać-Dević D, Stanković H, Bošković K. A method for determination of free fatty acids in serum. Clin Chim Acta 1973;45:55-59. [PubMed: 4712863]

Moeller FG, Dougherty DM, Swann AC, Collins D, Davis CM, Cherek DR. Tryptophan depletion and aggressive responding in healthy males. Psychopharmacology (Berl) 1996;126:97-103. [PubMed: 8856827]

Moja EA, Cipolla P, Castoldi D, Tofanetti O. Dose-response decrease in plasma tryptophan and in brain tryptophan and serotonin after tryptophan-free amino acid mixtures in rats. Life Sci 1989;44:971976. [PubMed: 2467158]

Moja EA, Rocchi E, Benedetti F, Paolillo F, Casalgrandi G, Ponz de Leon M. Decrease in plasma tryptophan after a tryptophan-free amino acid solution. A comparison between cirrhotic and control subjects. Life Sci 1991;48:409-418. [PubMed: 1992283]

Moja EA, Stoff DM, Gessa GL, Castoldi D, Assereto R, Tofanetti O. Decrease in plasma tryptophan after tryptophan-free amino acid mixtures in man. Life Sci 1988;42:1551-1556. [PubMed: 3352467]

Moore P, Landolt HP, Seifritz E, Clark C, Bhatti T, Kelsoe J, Rapaport M, Gillin JC. Clinical and physiological consequences of rapid tryptophan depletion. Neuropsychopharmacology 2000;23:601-622. [PubMed: 11063917] 
Murphy FC, Smith KA, Cowen PJ, Robbins TW, Sahakian BJ. The effects of tryptophan depletion on cognitive and affective processing in healthy volunteers. Psychopharmacology (Berl) 2002;163:4253. [PubMed: 12185399]

Nishizawa S, Benkelfat C, Young SN, Leyton M, Mzengeza S, de Montigny C, Blier P, Diksic M. Differences between males and females in rates of serotonin synthesis in human brain. Proc Natl Acad Sci 1997;94:5308-5313. [PubMed: 9144233]

Park SB, Coull JT, McShane RH, Young AH, Sahakian BJ, Robbins TW, Cowen PJ. Tryptophan depletion in normal volunteers produces selective impairments in learning and memory. Neuropharmacology 1994;33:575-588. [PubMed: 7984295]

Perugini M, Mahoney C, Ilivitsky V, Young SN, Knott V. Effects of tryptophan depletion on acute smoking abstinence symptoms and acute smoking response. Pharmacol Biochem Behav 2003;74:513-522. [PubMed: 12543214]

Pihl RO, Young SN, Harden P, Plotnick S, Chamberlain B, Ervin FR. Acute effect of altered tryptophan levels and alcohol on aggression in normal human males. Psychopharmacology (Berl) 1995;119:353360. [PubMed: 7480513]

Porter RJ, Lunn BS, Walker LLM, Gray JM, Ballard CG, O'Biran JT. Cognitive deficit induced by acute tryptophan depletion in patients with Alzheimer's Disease. Am J Psychiatry 2000;157:638-640. [PubMed: 10739429]

Riedel WJ, Sobczak S, Schmitt JA. Tryptophan modulation and cognition. Adv Exp Med Biol 2003;527:207-213. [PubMed: 15206734]

Rubinsztein JS, Rogers RD, Riedel WJ, Mehta MA, Robbins TW, Sahakian BJ. Acute dietary tryptophan depletion impairs maintenance of "affective set" and delayed visual recognition in healthy volunteers. Psychopharmacology (Berl) 2001;154:319-326. [PubMed: 11351939]

Schmitt JAJ, Jorissen BL, Sobczak S, van Boxtel MPJ, Hogervorst E, Deutz NEP, Reidel WJ. Tryptophan depletion impairs memory consolidation but improves focused attention in healthy young volunteers. J Psychopharamacol (Oxford) 2000;14:21-29.

Smith KA, Clifford EM, Hockney RA, Clark DM, Cowen PJ. Effect of tryptophan depletion on mood in male and female volunteers: A pilot study. Hum Psychopharmacol Clin Exp 1997;12:111-117.

Smith SE, Pihl RO, Young SN, Ervin FR. Elevation and reduction of plasma tryptophan and their effects on aggression and perceptual sensitivity in normal males. Aggress Behav 1986;12:393-407.

Sobczak S, Honig A, Nicolson NA, Riedel WJ. Effects of acute tryptophan depletion on mood and cortisol release in first-degree relatives of type I and type II bipolar patients and healthy matched controls. Neuropsychopharmacology 2002;27:834-842. [PubMed: 12431857]

Stancampiano R, Melis F, Sarias L, Cocco S, Cugusi C, Fadda F. Acute administration of a tryptophanfree amino acid mixture decreases 5-HT release in rat hippocampus in vivo. Am J Physiol 1997;272:R991-R994. [PubMed: 9087665]

Talbot PS, Watson DR, Barrett SL, Cooper SJ. Rapid tryptophan depletion improves decision-making cognition in healthy humans without affecting reversal learning or set shifting. Neuropsychopharmacology 2006;31:1519-1529. [PubMed: 16319909]

Van der Does AJ. The effects of tryptophan depletion on mood and psychiatric symptoms. J Affect Disord 2001;64:107-119. [PubMed: 11313078]

Walderhaug E, Lunde H, Nordvik JE, Landrø NI, Refsum H, Magnusson A. Lowering of serotonin by rapid tryptophan depletion increases impulsiveness in normal individuals. Psychopharmacology (Berl) 2002;164:385-391. [PubMed: 12457268]

Williams WA, Shoaf SE, Hommer D, Rawlings R, Linnoila M. Effects of acute tryptophan depletion on plasma and cerebrospinal fluid tryptophan and 5-hydroxyindoleacetic acid in normal volunteers. $\mathrm{J}$ Neurochem 1999;72:1641-1647. [PubMed: 10098872]

Weltzin TE, Fernstrom JD, McConaha C, Kaye WH. Acute tryptophan depletion in Bulimia: Effects on large neutral amino acids. Biol Psychiatry 1995;35:388-397. [PubMed: 8018785]

Wolfe BE, Metzger ED, Jimerson DC. Comparison of the effects of amino acid mixture and placebo on plasma tryptophan to large neutral amino acid ratio. Life Sci 1995;56:1395-1400. [PubMed: 8847950]

Young SN. The use of diet and dietary components in the study of factors controlling affect in humans: A review. J Psychiatry Neurosci 1993;18:235-244. [PubMed: 8297922] 
Young SN, Ervin FR, Pihl RO, Finn P. Biochemical aspects of tryptophan depletion in primates. Psychopharmacology (Berl) 1989;98:508-511. [PubMed: 2505291]

Young SN, Smith SE, Pihl RO, Ervin FR. Tryptophan depletion causes a rapid lowering of mood in normal males. Psychopharmacology (Berl) 1985;87:173-177. [PubMed: 3931142] 


\section{L-Tryptophan Depletion}
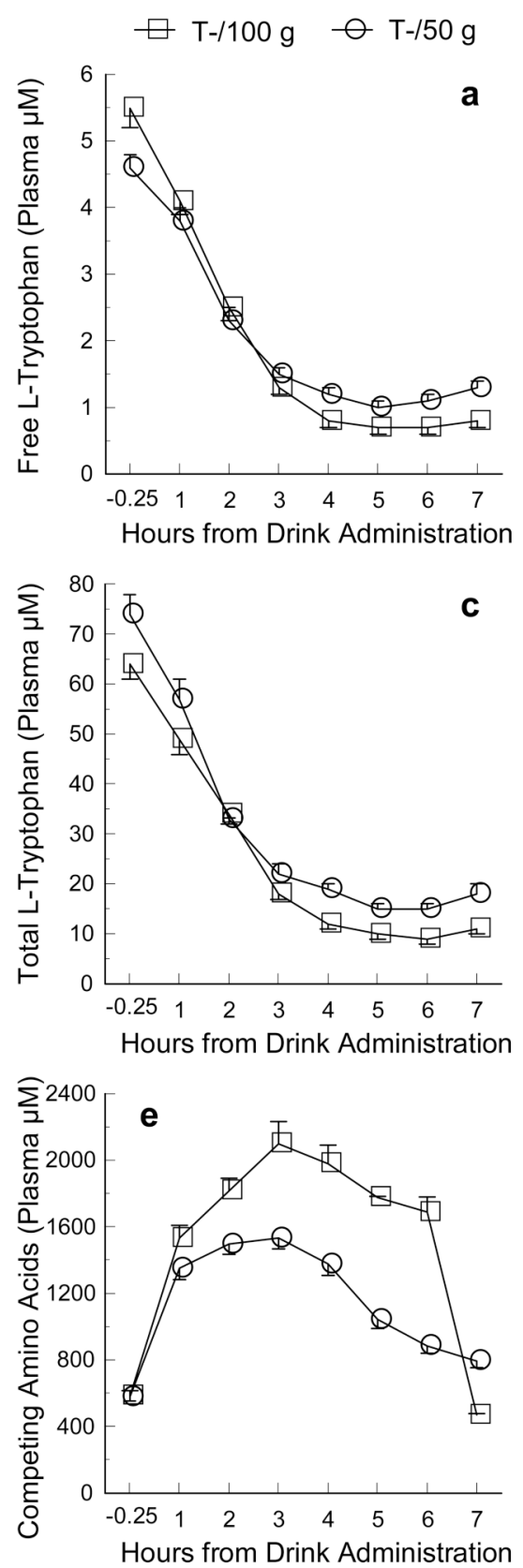

\section{L-Tryptophan Loading}
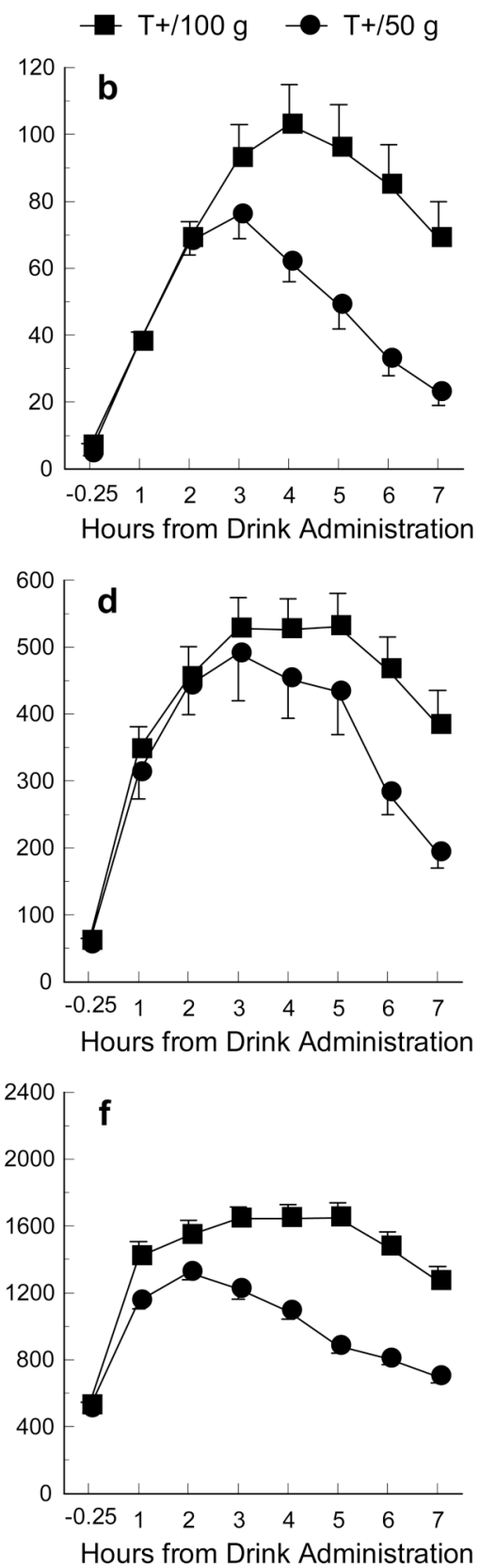

Figure 1.

Time-course of plasma free $L$-tryptophan [Free Trp], total $L$-tryptophan [Total Trp], and the sum of the competing amino acids [CAA] following both 50 and $100 \mathrm{~g} L$-tryptophan depletion (left panels) and loading (right panels) amino-acid formulations. Error bars represent SEM. 


\section{L-Tryptophan Depletion}
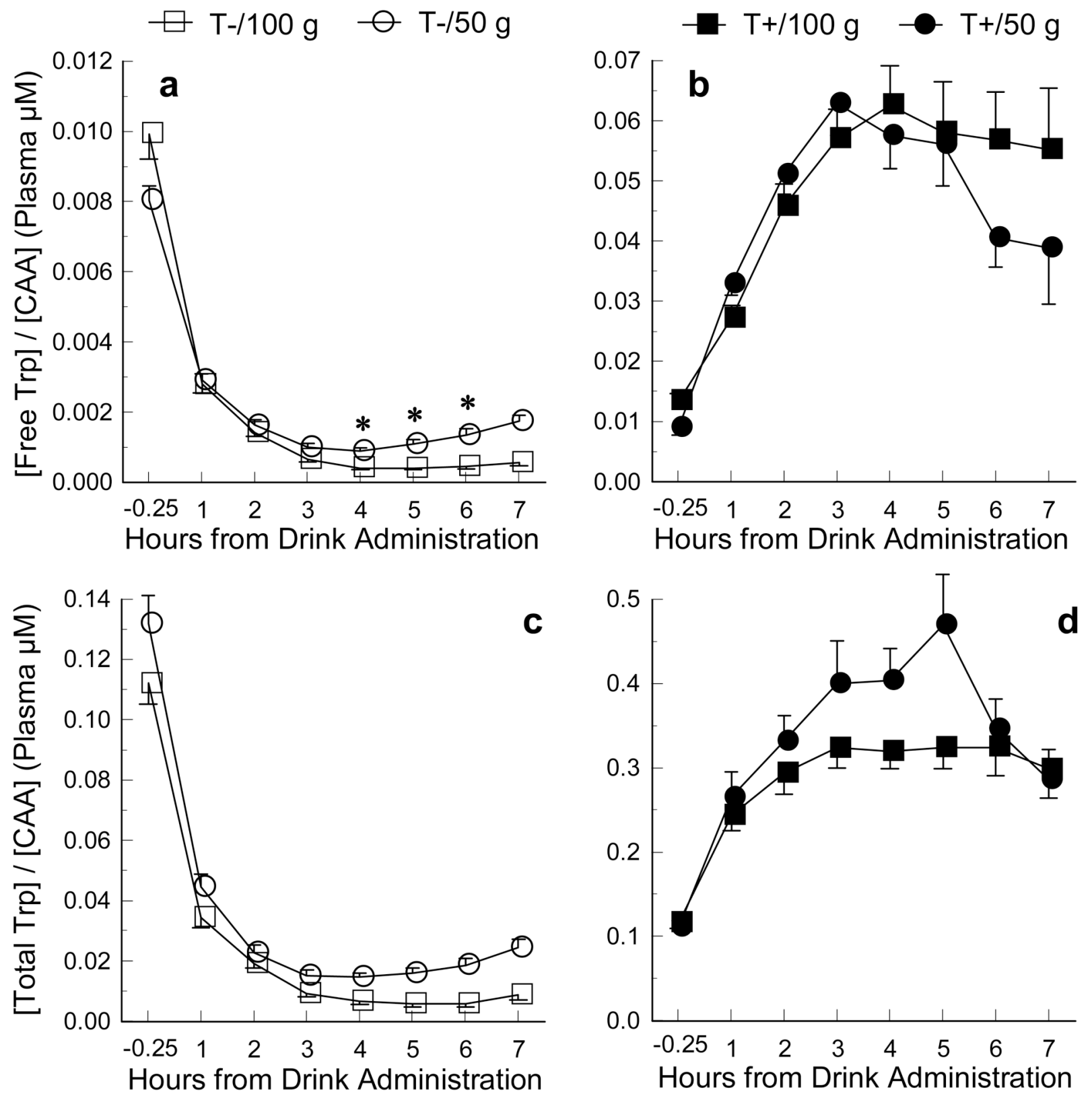

Figure 2.

Time-course of the [Free Trp] / [CAA] and [Total Trp] / [CAA] bioavailability ratios following both 50 and $100 \mathrm{~g} L$-tryptophan depletion (left panels) and loading (right panels) amino-acid formulations. Comparisons of the raw data for both depletion and loading formulations were conducted and statistically significant differences between the 50 and $100 \mathrm{~g}$ formulations are marked with an *. Error bars represent SEM. 


\section{Table 1}

Compositions of the low $(50 \mathrm{~g})$ and high $(100 \mathrm{~g})$ dose of $L$-tryptophan depletion, loading, and balanced mixtures

\begin{tabular}{|c|c|c|}
\hline$L$-tryptophan Formulation & $50 \mathrm{~g}$ & $100 \mathrm{~g}$ \\
\hline Trp Depletion & 0.00 & 0.00 \\
\hline Trp Loading & 5.15 & 10.30 \\
\hline Trp Balanced & 1.15 & --- \\
\hline \multicolumn{3}{|l|}{15 Amino Acids } \\
\hline L-alanine & 2.75 & 5.50 \\
\hline L-arginine & 2.45 & 4.90 \\
\hline L-cysteine & 1.35 & 2.70 \\
\hline Glycine hydromonochloride & 1.60 & 3.20 \\
\hline L-histidine & 1.60 & 3.20 \\
\hline L-isoleucine & 4.00 & 8.00 \\
\hline L-leucine & 6.75 & 13.50 \\
\hline L-lysine & 4.45 & 8.90 \\
\hline L-methionine & 1.50 & 3.00 \\
\hline L-phenylalanine & 2.85 & 5.70 \\
\hline L-proline & 6.10 & 12.20 \\
\hline L-serine & 3.45 & 6.90 \\
\hline L-threonine & 3.25 & 6.50 \\
\hline L-tyrosine & 3.45 & 6.90 \\
\hline L-valine & 4.45 & 8.90 \\
\hline
\end{tabular}



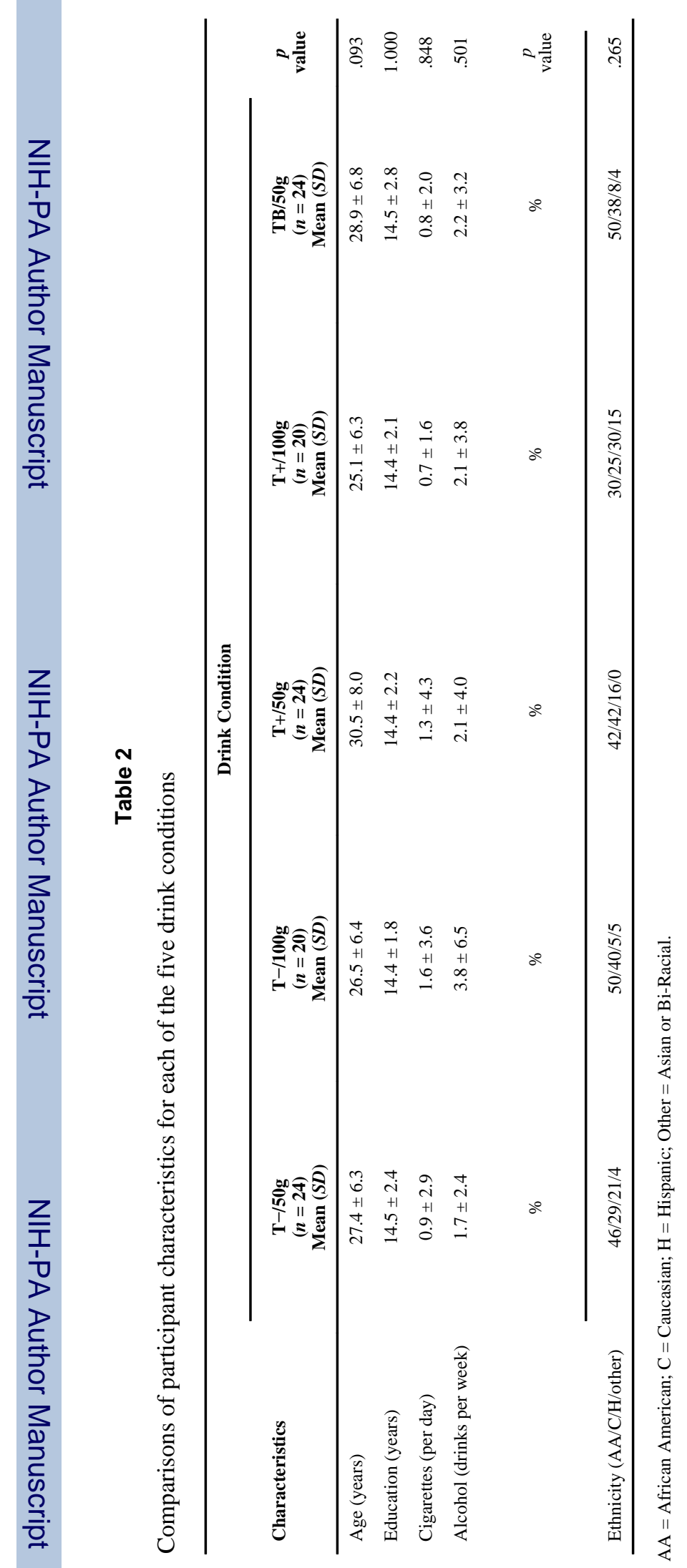

Psychopharmacology (Berl). Author manuscript; available in PMC 2010 February 9. 


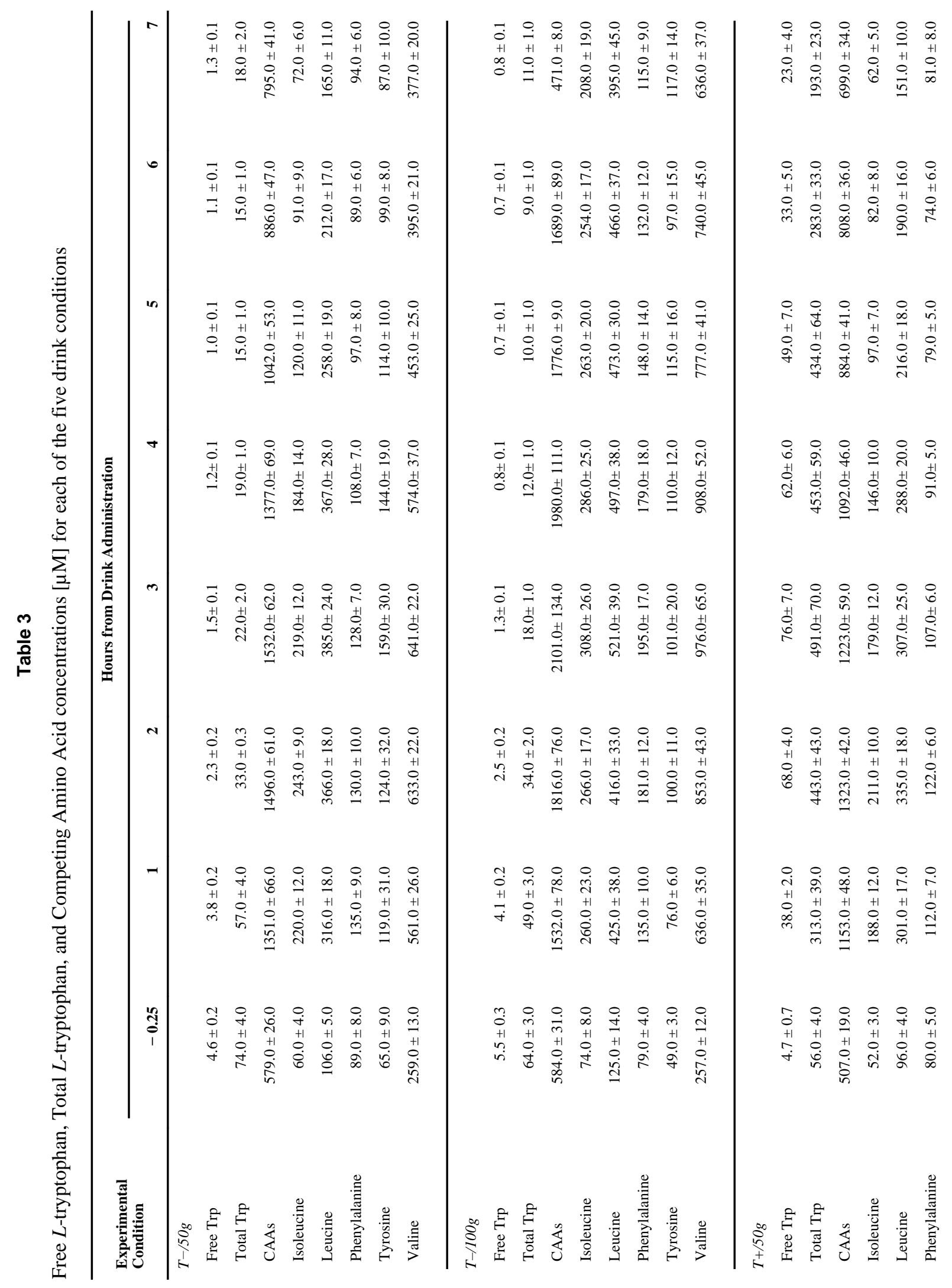




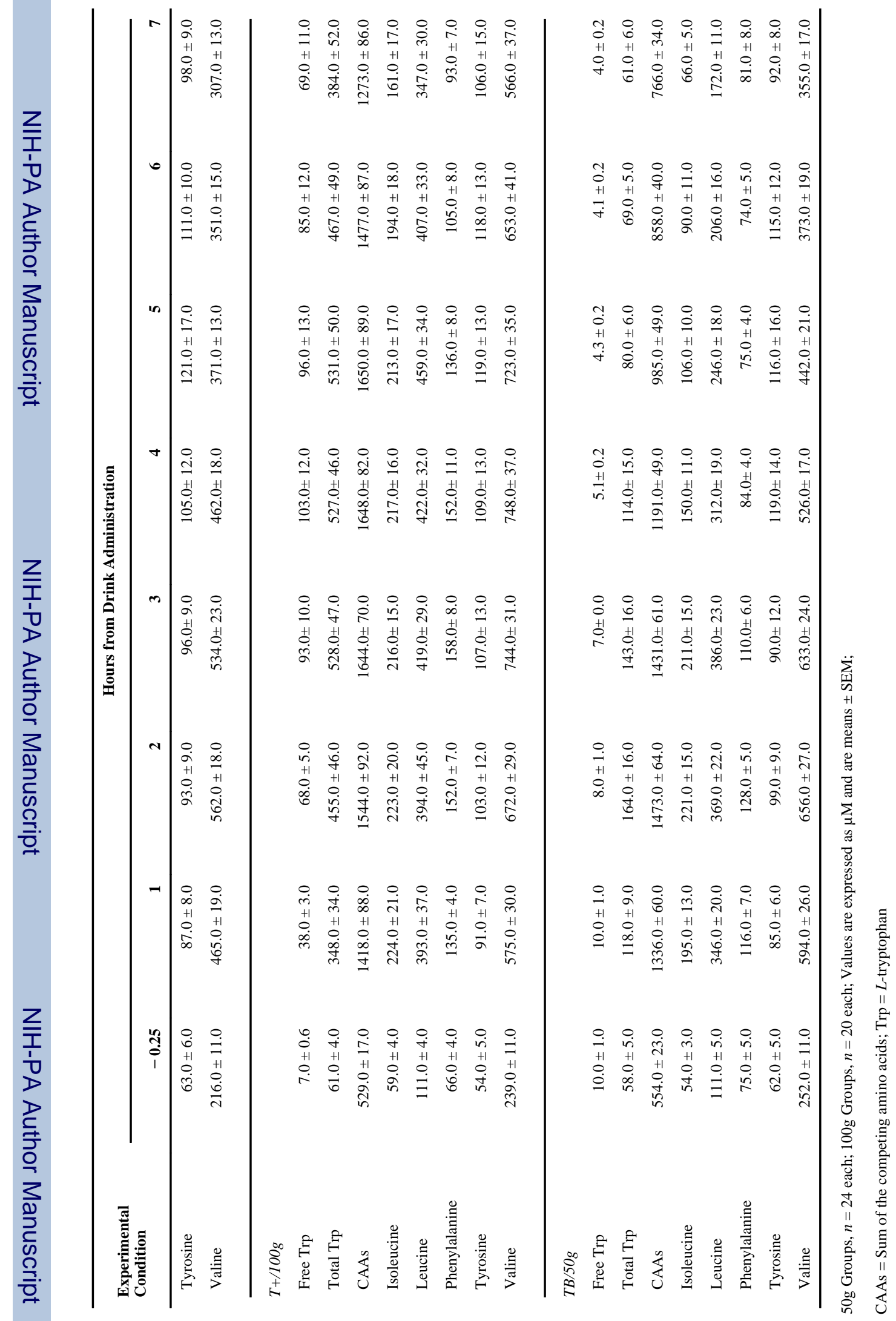

